DE

M E D I C I N A

T R O P I C A L

$\mathrm{DE}$

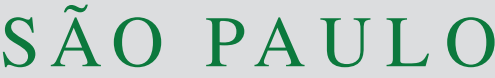

JOURNAL OF THE SÃO PAULO INSTITUTE OF TROPICAL MEDICINE

'Universidade Estadual de Maringá, Departamento de Análises Clínicas e Biomedicina, Maringá, Paraná, Brazil

${ }^{2}$ Hospital Universitário Regional de Maringá, Ambulatório Médico e de Enfermagem,

Maringá, Paraná, Brazil

Correspondence to: Vânia Ramos Sela da Silva

Universidade Estadual de Maringá,

Departamento de Análises Clínicas e

Biomedicina, Av. Colombo, 5790, CEP

87020-900, Maringá, PR, Brazil

Tel: +55 44 3011-4795

E-mail: vaniasela@gmail.com

Received: 10 June 2020

Accepted: 4 December 2020

\section{High molecular prevalence of HPV and other sexually transmitted infections in a population of asymptomatic women who work or study at a Brazilian university}

Tamy Taianne Suehiro', Fabrícia Gimenes ${ }^{1}$, Raquel Pantarotto Souza', Sergio Ken Iti Taura², Rita Cristina Cardoso Cestari², Mary Mayumi Taguti Irie', Cinthia Gandolfi Boer ${ }^{1}$, Marcia Edilaine Lopes Consolaro ${ }^{\circledR 1}$, Vânia Ramos Sela da Silva ${ }^{\circledR 1}$

\section{ABSTRACT}

Sexually transmitted infections (STIs) represent a global health problem with variable prevalence depending on the geographical region and the type of population. Human papillomavirus (HPV) encompasses widespread virus types related to cervical carcinogenesis. The present study investigated the molecular prevalence of HPV and seven other important STIs in asymptomatic women working or studying at a Brazilian university. A secondary aim was to assess cytological abnormalities associated with HPV and other STIs coinfections. We recruited 210 women from a Brazilian university. HPV was detected using a single-round polymerase chain reaction ( $\mathrm{SPCR}$ ) followed by a viral genotyping by restriction fragment length polymorphism (RFLP-PCR). The presence of seven STIs: Chlamydia trachomatis, Neisseria gonorrhoeae, Treponema pallidum, Trichomonas vaginalis, Mycoplasma genitalium, herpes simplex virus (HSV)-1 and HSV-2 was detected by multiplex PCR (M-PCR). Furthermore, cytological findings and epidemiological characteristics were evaluated.The mean age of the participants was 27.1 years old. HPV prevalence was $33.8 \%$, and HPV16 was the most frequently detected papillomavirus genotype. Moreover, multiple HPV infections were common (42.2\%). We detected at least one STI agent in $11.4 \%$ of the tested women, most frequently $C$. trachomatis (6.7\%). Among HPV-positive women, $14.1 \%$ were coinfected with other STI agents. Cytological abnormalities were observed in $9.5 \%$ of smears, and HPV-DNA, high-risk HPV (HR-HPV), HPV16 and HPV multiple infections were associated with abnormal cytological findings. There was a high prevalence of HPV, and C. trachomatis was the most prevalent STI agent, with low rates of cytological abnormalities. These findings highlight the need of timely STI diagnosis in young asymptomatic women and of a public policy design for STI prevention.

KEYWORDS: Sexually transmitted infections. Papillomavirus infections. Uterine cervical neoplasms. Screening. Polymerase chain reaction.

\section{INTRODUCTION}

Sexually transmitted infections (STIs) represent a great global health problem directly impacting women's sexual and reproductive health. More than one million individuals are infected daily by a STI worldwide, and approximately 300 million people have acquired one of the four curable STIs, Chlamydia trachomatis (C. trachomatis), Neisseria gonorrhoeae (N. gonorrhoeae), Treponema pallidum (T. pallidum), and Trichomonas vaginalis (T. vaginalis). The incidence 
of viral STIs is also high; every year an estimated over 290 million individuals experience infections caused by human papillomavirus (HPV) worldwide ${ }^{1}$. The majority of infections caused by sexually curable agents are asymptomatic and treatable; however, when untreated or treated incorrectly, they can lead to severe health complications, particularly in women, such as infertility, pelvic inflammatory disease, ectopic pregnancy ${ }^{1,2}$, and an increased risk of human immunodeficiency virus (HIV) infection ${ }^{1,3}$. Therefore, it is urgent that the public health community make effective interventions for STI prevention, screening, diagnosis, and treatment available ${ }^{4}$.

Cervical cancer (CC) is the fourth most common neoplasm regarding the incidence and mortality in women worldwide ${ }^{5}$. HPV is necessary, but not sufficient for cervical carcinogenesis. Many factors may be associated with high-risk HPV (HR-HPV) and play an important role in viral persistence, contributing to cancer development ${ }^{6,7}$. Cofactors associated with the individual's behaviours include the age at the first intercourse, multiple sexual partners, host genetic variability, and use of tobacco and oral contraceptives $^{7-9}$. Furthermore, coinfection with bacterial vaginosis ${ }^{10}$ and other STIs may be associated with increased risk of high-grade squamous intraepithelial cervical lesions (HSIL) and squamous cervical cancer (SCC) ${ }^{11,12}$.

STIs prevalence in women has been extensively investigated and presents with variable rates depending on the study population and the diagnostic methods employed ${ }^{11-13}$. However, prevalence studies on asymptomatic non-HPV STIs are scarce in university populations, as are investigations of HPV-related coinfections.

The present study investigated the prevalence of HPV and seven other important STIs in asymptomatic women from a Parana State university, in Brazil. A secondary objective was to assess cytological abnormalities associated with HPV and other STIs coinfections. We detected a high prevalence of HPV and STIs, especially of C. trachomatis accompanied by low rates of cytological abnormalities, highlighting the need to adopt public policies for the prevention and early diagnosis of STIs in young and asymptomatic women.

\section{MATERIALS AND METHODS}

\section{Study population}

In this transversal study, 210 women aged 18-50 years old were recruited by convenience between August 2014 and November 2015. All participants had already had a sexual intercourse, lived in Maringa city, Parana State, Brazil, and were students or employees of the State University of Maringa (UEM), Parana State, Brazil.
Any of the following factors were considered exclusion criteria: pregnancy, postpartum period, previous hysterectomy, vaginal bleeding, previous history of cancer, no history of sexual activity, recent treatment for any pathology of the urogenital tract, ablative or excisional therapy to the cervix within the previous 12 months, and no observation and/ or sample collection of squamous columnar junction (SCJ).

All participants voluntarily provided a sample for the Papanicolaou (Pap) screening and HPV-DNA detection and non-HPV STIs detection; furthermore, all participants gave their written informed consent before the enrolment. The study was approved by the Committee for Ethics in Research Involving Humans of the State University of Maringa, UEM, Brazil (CAAE 30838314.9.0000.0104; permission 687.955/2014).

\section{Study procedures}

The participants answered a questionnaire on demographic characteristics, lifestyle and sexual behaviour. The information included age, self-declared skin color, marital status, childbirth, number of sexual partners during the lifespan, age of first intercourse, smoking habit, oral contraceptive use, and cervical cauterization.

Vaginal, cervical and endocervical samples were collected by the Ayres's spatula and a cytobrush for the Pap smear preparation. Cytological smears were stained using the Papanicolaou technique and evaluated by a cytopathologist according to the Bethesda System diagnostic criteria $^{14}$. The cytological findings were classified as negative for squamous intraepithelial lesion or malignancy (NILM), atypical squamous cells of undetermined significance (ASC-US) or could not exclude squamous intraepithelial lesions of high-grade (ASC-H), low-grade squamous intraepithelial lesions (LSIL), highgrade squamous intraepithelial lesions (HSIL) and invasive cervical cancer (CC). The follow-up of positive patients (ASC-US or more severe cytologic changes) were carried out according to the Brazilian guidelines for $\mathrm{CC}$ screening ${ }^{15}$.

For molecular procedures, samples were immediately suspended in $1.0 \mathrm{~mL}$ of sterile $0.9 \% \mathrm{NaCl}_{2}$ solution and stored at $-80^{\circ} \mathrm{C}$ until analysis.

\section{Genomic DNA extraction}

Samples were incubated for $15 \mathrm{~min}$ with proteinase $\mathrm{K}$ in phosphate-buffered saline and then centrifuged for $30 \mathrm{~s}$ at $6,800 \mathrm{~g}$. DNA extraction was performed with the Purelink viral RNA/ DNA ${ }^{\circledR}$ kit (Invitrogen, Thermo Fisher Scientific, Waltham, MA, USA) according to the manufacturer's 
instructions. The quality and quantity of purified DNA were evaluated using a spectrophotometer (NanoDrop 2000 Spectrophotometer, Thermo Fisher Scientific, Waltham, MA, USA).

Single-round PCR (sPCR) for HPV detection and HPV genotyping by restriction fragment length polymorphism (RFLP-PCR)

HPV was detected using a SPCR with the primers MY09 (5'-CGTCCM AARGGAWACTGATC-3') and MY11 (5'-GCMCAGGGWCATAAYAATGG-3') as described previously ${ }^{16}$. PCR was performed using the following conditions: 5 min of denaturation at $94{ }^{\circ} \mathrm{C} ; 30$ cycles of denaturation at $94{ }^{\circ} \mathrm{C}$ for $30 \mathrm{~s}$, annealing at $55^{\circ} \mathrm{C}$ for $60 \mathrm{~s}$, and extension at $72{ }^{\circ} \mathrm{C}$ for $60 \mathrm{~s}$; and a final extension step at $72{ }^{\circ} \mathrm{C}$ for $8 \mathrm{~min}$ (Thermal cycler, Applied Biosystems, Foster City, CA, USA). This reaction produced a final amplification product of 450 base pairs (bp). The DNA quality was tested by the amplification of a 268 bp gene fragment of the human $\beta$-globin gene using the primers GH20 (5'-GAAGAGCCAAGGACAGGTAC-3') and PC04 (5'-C AACTTCATCCACGTTCACC-3') under identical conditions as the ones of the HPV-PCR. Two types of controls were used in the reaction: a sample without DNA (negative control) and an HPV-positive cervical sample (positive control).

The final amplification products were loaded onto a $1 \%$ agarose gel stained with $150 \mathrm{ng} / \mu \mathrm{L}$ ethidium bromide and subjected to electrophoresis in a horizontal apparatus at $110 \mathrm{~V}$ for $45 \mathrm{~min}$ in $0.5 \times \mathrm{TBE}$ buffer $(45 \mathrm{mM}$ Tris-borate, 1 mM EDTA, pH 8.0). A 100 bp marker (Invitrogen, Thermo Fisher Scientific, Waltham, MA, USA) was used as a molecular size marker. The amplified DNA fragments were visualized in a transilluminator with UV light and photographed.

HPV-positive samples were genotyped by RFLP analysis, in which amplified DNA was cleaved with restriction enzymes to generate DNA fragments of different molecular sizes. Aliquots of each amplification product were subjected to digestion with the restriction enzyme HpyCH4V (New England Biolabs, Ipswich, MA, USA) ${ }^{17}$. To better differentiate between HPV genotypes with similar RFLP patterns, such as HPV11/30, 18/68, 44/55 and $61 / 83 / 84$, a second restriction enzyme was used (NlaIII, New England Biolabs, Ipswich, MA, USA) ${ }^{18}$. The restriction digest fragments were then subjected to electrophoresis on $8 \%$ polyacrylamide gels. Both, 100 and 25 bp ladders (Invitrogen, Carlsbad, CA, USA) were used as molecular sizemarkers. After electrophoresis, polyacrylamide gels were analysed with the LabImage ID software (Loccus
Biotechnology, Cotia, Sao Paulo, Brazil), and the size of each fragment was determined. Genotyping was performed by comparing the molecular weights of the fragments for each HPV genotype as described by Santiago et al. ${ }^{17}$. A total of 40 individual HPV genotypes were determined by PCR-RFLP: 11 genotypes are considered high-risk (HR-HPV: 16, 18, 31, 33, 35, 39, 45, 51, 52, 56 and 58); 11 are probably oncogenic $(26,30,34,53,66,67,68,69$, 70,73 and 82 ), and 18 are low-risk genotypes (LR-HPV) that are not associated with carcinogenesis $(6,11,40,42$, $43,44,54,55,61,62,64,69,72,74,81,83,84$, and 91) ${ }^{19}$.

The patients positively diagnosed for HPV were requested to repeat the tests after 6 months, for the followup and to verify the presence of viruses.

\section{Simultaneous detection of seven important STIs by multiplex PCR (M-PCR)}

A M-PCR was performed to simultaneously detect C. trachomatis, $N$. gonorrhoeae, $M$. genitalium, $T$. vaginalis, HSV-1, HSV-2, and T. pallidum as previously described by Souza et al..$^{13}$ (Table 1). M-PCR was carried out using the following conditions: $10 \mathrm{~min}$ of denaturation at $94{ }^{\circ} \mathrm{C}$; 35 cycles of denaturation at $94{ }^{\circ} \mathrm{C}$ for $60 \mathrm{~s}$, annealing at $62{ }^{\circ} \mathrm{C}$ for $60 \mathrm{~s}$, and extension at $72{ }^{\circ} \mathrm{C}$ for $60 \mathrm{~s}$; and a final extension step at $72^{\circ} \mathrm{C}$ for $10 \mathrm{~min}$ (Thermal cycler, Applied Biosystems, Thermo Fisher Scientific, Waltham, MA, USA). The M-PCR products were electrophoresed on an 8\% polyacrylamide gel. Positive controls for all analysed STIs were from positive clinical samples detected using reference methods, including culture and/ or sPCR. All clinical samples were also tested by using human $\beta$-globinspecific primers and $\mathrm{GH} 20 / \mathrm{PC} 04$ as an internal control of amplification and of DNA integrity, under the same conditions of the M-PCR. The patients positively diagnosed for ISTs were followed-up and treated according to the Brazilian Clinical Protocol and Therapeutic Guidelines ${ }^{20}$.

\section{Statistical analysis}

Statistical analysis was performed with the software GraphPad Prism 6.0 (San Diego, California, USA), and the statistical significance was set at $P<0.05$. Different variables were evaluated for comparisons and analytical calculations based on the presence of HPV and STIs. A two-sided Fisher's exact test with $2 \times 2$ contingency tables was used to evaluate statistically significant differences between groups. Crude odds ratios (OR) with 95\% confidence intervals (CI) were calculated to estimate the association of HPV and STI positive results with different cytological findings. 
Table 1 - Oligonucleotide primers used in the multiplex-PCR assays.

\begin{tabular}{|c|c|c|c|}
\hline Pathogens & Primers & Oligonucleotide (5’- 3’) & Amplicon size $\left(\mathrm{bp}^{*}\right)$ \\
\hline CT & Foward Reverse & $\begin{array}{l}\text { TCTTTTTAAACCTCCGGAACCCACTT } \\
\text { GGATGGCATCGCATAGCATTCTTTG }\end{array}$ & 361 \\
\hline HSV-1 & Foward Reverse & $\begin{array}{l}\text { CTGTGGTGTTTTTGGCATCA } \\
\text { GGTTGTGGAGGAGACGTTG }\end{array}$ & 123 \\
\hline HSV-2 & Foward Reverse & $\begin{array}{l}\text { CATGGGGCGTTTGACCTC } \\
\text { TACACAGTGATCGGGATGCT }\end{array}$ & 249 \\
\hline MG & Foward Reverse & $\begin{array}{l}\text { ACCTTGATGGTCAGCAAAACTT } \\
\text { CCTTTGATCTCATTCCAATCAGTA }\end{array}$ & 193 \\
\hline NG & Foward Reverse & $\begin{array}{l}\text { CGGCAGCATTCAATTTTGTT } \\
\text { AAAAAGCCGCCATTTTTGTA }\end{array}$ & 162 \\
\hline TP & Foward Reverse & $\begin{array}{l}\text { GGAGAAGTTTCACTTCGTGGA } \\
\text { CTCGCGTCATCACCGTAGTA }\end{array}$ & 291 \\
\hline TV & Foward Reverse & $\begin{array}{l}\text { CCAGAAGTGGGCTACACACC } \\
\text { ATACCAAGGCCGGAAGCAC }\end{array}$ & 170 \\
\hline
\end{tabular}

CT = Chlamydia trachomatis; HSV-1/2 = Herpes simplex virus; MG = Micoplasma genitalium; NG = Neisseria gonorrhoeae; $\mathrm{TP}=$ Treponema pallidum; TV $=$ Trichomonas vaginalis; $\mathrm{Bp}^{*}=$ base pairs.

\section{RESULTS}

\section{Population characteristics}

A total of 210 women were enrolled in the study, including 166 students (79.0\%), 26 employees (12.4\%) and 18 participants who did not inform their roles at the University $(8.6 \%)$. The mean age of the examined population was 27.1 years (range $18-50$ years). The majority of the participants were white $(85.2 \%)$, single (80.0\%), and had never been pregnant (75.2\%). Oral contraceptive use was frequent (60.0\%), whereas smoking was relatively rare $(8.1 \%)$. Most women $(60.5 \%)$ had their first sexual intercourse before the age of 18 years old (range 13-39), the majority had a current sexual partner $(72.4 \%)$ and more than one partner during their lives $(68.1 \%)$ (Table 2).

\section{Prevalence of HPV and seven other important STIs}

HPV DNA was detected in 71 women $(33.8 \%)$ aged $25.9 \pm 7.35$ years, by means of sPCR. Twenty-nine HPV types were identified (Table 3 ), including $10 \mathrm{HR}-\mathrm{HPV}$ (16, $18,31,33,39,45,51,56,58$, and 59), 7 probably oncogenic HPV (26, 66, 68, 69, 70, 73, and 82), and 12 LR-HPV (6, 11, 13, 43, 54, 61, 62, 64, 72, 74, 81, and 83). HPV16 (31.0\%, $\mathrm{n}=22 / 71)$, HPV70 and HPV82 $(11.3 \%, \mathrm{n}=8 / 71$ each) represented the most frequently identified genotypes. HPV16 was the most common genotype in mono-infections, as well as in multiple infections with frequencies of $18.0 \%$ $(\mathrm{n}=13 / 71)$ and $12.7 \%(\mathrm{n}=9 / 71)$, respectively.

Among HPV-DNA-positive women ( $\mathrm{n}=71$ ), HR-HPV genotypes, probably oncogenic types, and LR-HPV were detected in $59.1 \%(\mathrm{n}=42 / 71), 16.9 \%(\mathrm{n}=12 / 71)$ and $24 \%$
( $\mathrm{n}=17 / 71)$, respectively. Multiple HPV genotypes infections were very common, being detected in $42.2 \%$ of the total infections $(n=30 / 71)$. Twenty-eight of these participants (93.3\%) were infected by two HPV genotypes, and two patients $(6.7 \%)$ by three HPV types.

At least one STI agent was detected in $11.4 \%$ of the participants $(n=24 / 210)$ by M-PCR. The identified species included C. trachomatis $(6.7 \% ; \mathrm{n}=14 / 210)$, T. pallidum $(1.9 \% ; \mathrm{n}=4 / 210), \operatorname{HSV}-2(0.5 \%, \mathrm{n}=1 / 210), N$. gonorrhoeae $(0.5 \%, \mathrm{n}=1 / 210), T$. vaginalis $(0.5 \%, \mathrm{n}=1 / 210), \mathrm{HSV}-1$ and $M$. genitalium coinfection $(0.5 \%, \mathrm{n}=1 / 210), \mathrm{HSV}-1$ and $T$. vaginalis coinfection $(0.5 \%, \mathrm{n}=1 / 210)$, and $\mathrm{HSV}-2$ and $N$. gonorrhoeae coinfection $(0.5 \%, \mathrm{n}=1 / 210)$. Figure 1 shows the frequency of STI agents detected by M-PCR in all cases $(n=24)$. All individuals who tested positive for STIs were asymptomatic.

Among HPV-positive women, $14.1 \%(n=10 / 71)$ were coinfected with other STI agents. The most frequent coinfection was with $C$. trachomatis $(50.0 \%$; $\mathrm{n}=5 / 10)$, followed by T. pallidum $(20.0 \% ; \mathrm{n}=2 / 10)$. N. gonorrhoeae, T. vaginalis, and $M$. genitalium coinfections with HSV-1 were also observed $(10.0 \% ; n=1 / 10$; one case each). The HPV genotypes implicated in STI coinfections are shown in Table 4. Table 2 shows the characteristics of women positive for HPV and STIs and that participants with 25 years or younger as well as the ones that had more than one partner during their lives were associated with having HPV infection ( $P=0.02$ for both analyses).

\section{Cytological findings}

Most Pap smear results were NILM (90.5\%, $\mathrm{n}=190 / 210$ ). Cytological abnormalities were observed in 
Table 2 - Characteristics of the study population based on the detection of HPV-DNA and other STI agents.

\begin{tabular}{|c|c|c|c|c|c|c|c|}
\hline \multirow[t]{2}{*}{ Overall } & $\begin{array}{c}\text { Total } \\
(n=210)\end{array}$ & $\begin{array}{l}\mathrm{HPV}- \\
(n=139)\end{array}$ & $\begin{array}{l}\mathrm{HPV}+ \\
(\mathrm{n}=71)\end{array}$ & \multirow[t]{2}{*}{$P$} & $\begin{array}{c}\text { STI - } \\
(n=186)\end{array}$ & $\begin{array}{c}\mathrm{STI}+ \\
(\mathrm{n}=24)\end{array}$ & \multirow[t]{2}{*}{$P$} \\
\hline & \multicolumn{3}{|c|}{ n (\%) } & & \multicolumn{2}{|c|}{$\mathrm{n}(\%)$} & \\
\hline \multicolumn{8}{|l|}{ Age (years) } \\
\hline$\leq 25$ & $122(58.1)$ & $73(52.5)$ & $49(69.0)$ & 0.02 & $106(57.0)$ & $16(66.7)$ & 0.39 \\
\hline 25 & $88(41.9)$ & $66(47.5)$ & $22(31.0)$ & & $80(43.0)$ & $8(33.3)$ & \\
\hline \multicolumn{8}{|l|}{ Skin color* } \\
\hline White & $179(85.2)$ & $119(85.6)$ & $60(84.5)$ & 0.54 & $159(85.5)$ & 20 (83.3) & 0.16 \\
\hline Not white & $12(5.7)$ & $7(5.0)$ & $5(7.0)$ & & $9(4.8)$ & $3(12.5)$ & \\
\hline \multicolumn{8}{|l|}{ Civil status* } \\
\hline Single & $168(80.0)$ & $108(77.7)$ & $60(84.5)$ & 0.23 & 145 (77.9) & $23(95.8)$ & - \\
\hline Married & $33(15.7)$ & $25(18.0)$ & $8(11.3)$ & & $33(17.7)$ & $0.0(0)$ & \\
\hline \multicolumn{8}{|c|}{ Number of pregnancies* } \\
\hline 0 & $158(75.2)$ & $101(72.7)$ & $57(44.5)$ & 0.32 & $136(73.1)$ & $22(91.7)$ & 0.08 \\
\hline$\geq 1$ & $35(16.7)$ & $26(18.7)$ & $9(12.7)$ & & 34 (18.3) & $1(4.2)$ & \\
\hline \multicolumn{8}{|c|}{ Age of first sexual intercourse ${ }^{*}$} \\
\hline$\leq 18$ & $127(60.5)$ & $80(57.5)$ & $47(66.2)$ & 0.21 & $112(60.2)$ & $15(62.5)$ & $>0.99$ \\
\hline 18 & $71(33.8)$ & $51(36.7)$ & $20(28.2)$ & & $74(39.8)$ & $9(37.5)$ & \\
\hline \multicolumn{8}{|c|}{ Smoking habit* } \\
\hline Yes & $17(8.1)$ & $10(7.2)$ & $7(9.9)$ & 0.59 & $15(8.1)$ & $2(8.3)$ & $>0.99$ \\
\hline No & $182(86.7)$ & $122(87.8)$ & $60(84.5)$ & & $161(86.6)$ & $21(87.5)$ & \\
\hline \multicolumn{8}{|c|}{ Oral contraceptive use* } \\
\hline Yes & $126(60.0)$ & $80(57.5)$ & $46(64.8)$ & 0.44 & $110(59.1)$ & $16(66.7)$ & 0.49 \\
\hline No & $79(37.6)$ & $55(39.6)$ & $24(33.8)$ & & $72(38.7)$ & 7 (29.2) & \\
\hline \multicolumn{8}{|c|}{ Current sexual partner* } \\
\hline Yes & $152(72.4)$ & $104(74.8)$ & $48(67.6)$ & 0.29 & $137(73.6)$ & $15(62.5)$ & 0.19 \\
\hline No & $47(22.4)$ & $28(20.1)$ & $19(26.8)$ & & $39(21.0)$ & 8 (33.3) & \\
\hline \multicolumn{8}{|c|}{ More than one partner during the life* } \\
\hline Yes & $143(68.1)$ & $87(62.6)$ & $56(78.9)$ & 0.02 & $128(68.8)$ & $15(62.5)$ & 0.32 \\
\hline No & $51(24.3)$ & $40(28.8)$ & $11(15.5)$ & & $43(23.1)$ & $8(33.3)$ & \\
\hline
\end{tabular}

${ }^{*}$ Certain data were not informed by the participants of the study.

$9.5 \%(n=20 / 210)$ of the smears, including 15 women with ASC-US $(7.1 \%, \mathrm{n}=15 / 210)$ and five with LSIL $(2.4 \%$, $\mathrm{n}=5 / 210$ ). No evidence of ASC-H, HSIL or CC was detected.

Among the HPV-positive women, 76.1\% ( $n=54 / 71)$ had NILM. Furthermore, 23.9\% $(\mathrm{n}=17 / 71)$ presented with abnormal cytology, including $16.9 \%$ with ASC-US $(n=12 / 71)$ and $7.0 \%$ with LSIL $(n=5 / 71)$. In the positive women for STIs as determined by M-PCR, $87.5 \%$ had a NILM cytology $(n=21 / 24)$, and among them three $(12.5 \%)$ had cytological abnormalities, including two with ASC-US $(8.3 \%)$ and one with LSIL (4.2\%). Among women with ASC-US, one was positive for C. trachomatis and one for T. vaginalis, whereas the woman with LSIL was positive for $C$. trachomatis.
Table 5 shows the statistically significant association of HPV-DNA, HR-HPV, HPV16 and HPV-multiple infections with the presence of cytological abnormalities in the Pap test $(P<0.0001 ; P<0.0001 ; P<0.0001$ and $P=0.001$ respectively). There was a marginal statistical difference in the presence of coinfection of HPV and other STI agents with abnormal cytology $(P=0.056)$.

\section{DISCUSSION}

The present study shows a prevalence of HPV-DNA (33.8\%) and seven other important STIs (11.4\%), including C. trachomatis, N. gonorrhoeae, M. genitalium, T. vaginalis, HSV-1, HSV-2, and T. pallidum, in asymptomatic women 
Table 3 - Identification of HPV genotypes according to their oncogenic potential (oncogenic, probably oncogenic, and non-oncogenic genotypes) in the total of HPV-positive women group $(n=71)$.

\begin{tabular}{lcc}
\hline HPV genotypes & \multicolumn{2}{c}{ Total HPV+ group $(\mathrm{n}=71)^{\star}$} \\
\cline { 2 - 3 } & $\mathrm{N}$ & $\%$ \\
\hline High-risk HPV genotypes & & 31.0 \\
\hline 16 & 22 & 2.8 \\
18 & 2 & 7.0 \\
31 & 5 & 1.4 \\
33 & 1 & 1.4 \\
39 & 1 & 1.4 \\
45 & 1 & 2.8 \\
51 & 2 & 2.8 \\
56 & 2 & 4.2 \\
58 & 3 & 8.5 \\
59 & 6 & \\
\hline
\end{tabular}

\begin{tabular}{lcc}
\hline Probably oncogenic HPV genotypes & \\
\hline 26 & 4 & 5.6 \\
66 & 2 & 2.8 \\
68 & 2 & 2.8 \\
69 & 1 & 1.4 \\
70 & 8 & 11.3 \\
73 & 2 & 2.8 \\
82 & 8 & 11.3 \\
\hline Low-risk HPV genotypes & & \\
\hline 6 & 5 & 7.0 \\
11 & 4 & 5.6 \\
13 & 1 & 1.4 \\
43 & 4 & 5.6 \\
54 & 1 & 1.4 \\
61 & 2 & 2.8 \\
62 & 1 & 8.5 \\
64 & 6 & 1.4 \\
72 & 1 & 4.2 \\
74 & 3 & 1.4 \\
81 & 1 & 1.4 \\
83 & 1 & \\
\hline
\end{tabular}

${ }^{*}$ This group considered the coinfections with more than one HPV genotype (multiple infections).

at a Brazilian university. The majority of participants were students (79.0\%) and most positive women for HPV and STIs were younger than 25 years $(69.0 \%$ and $66.7 \%$, respectively). Although we have detected a high prevalence of HPV, the rate of cervical cytological abnormalities was low $(9.5 \%)$. Furthermore, the rates of HPV-multiple infections were also high (42.2\%) while the most prevalent HPV was HPV16.

In our study, the HPV rate was high as was the case of other Brazilian universities in the Northern and Central regions, in which frequencies of $25.5 \%$ and $47 \%$ were found, respectively ${ }^{21,22}$. Studies carried out at universities in different regions of the world found rates similar to ours $^{23,24}$. In general, HPV prevalence studies have shown that the HPV-DNA detection rate in cervical specimens may vary depending on the investigated geographic place, with a higher prevalence in younger women aged 25 or less, which later decreases visibly in middle-age women ${ }^{25}$.

The identification of HPV genotypes is relevant for the prophylaxis and treatment of the disease. The detection of HR-HPV is very important due to its greater propensity to persist and lead to the development of precancerous lesions and $\mathrm{CC}^{6,7,8,25}$. In our study, $59.1 \%$ of the HPV-positive women presented with HR-HPVs; genotype 16 was the most common among the genotypes and was followed by genotypes 70 and 82 . Worldwide data on HPV genotypes prevalence have shown that genotype 16 is most widely distributed globally, followed by genotype 18; these two together are responsible for about $71 \%$ of all cervical cancers. Furthermore, the second most frequent HPV genotype may vary in different geographical regions ${ }^{25}$. Interestingly, the other HPV genotypes that were more commonly observed in our study (HPV70 and HPV82) are classified as probably oncogenic genotypes and are not included in currently available HPV vaccines.

The presence of multiple HPV genotypes was frequent in our study (42.2\%). Previous investigations of Brazilian university students have shown the presence of multiple HPV genotypes infection in $41 \%$ to $54.3 \%$ of women ${ }^{21,22}$. C. trachomatis, T. pallidum, N. gonorrhoeae, T. vaginalis, HSV-2, and coinfections between HSV-1 and T. vaginalis, HSV-1 and M. genitalium, and finally $N$. gonorrhoeae and HSV-2 were detected in this study. Among young women, genital C. trachomatis is the most prevalent bacterial STI ${ }^{1}$. Accordingly, in our investigation C. trachomatis was the most frequent species (6.7\%), followed by T. pallidum.

C. trachomatis prevalence in asymptomatic women has already been examined ${ }^{26,27}$. In studies conducted in different Brazilian regions, $C$. trachomatis genital infection rates varied and these differences may be related to the methodology of detection and the population profile ${ }^{12,27,28}$. The mean age among women infected with $C$. trachomatis in our study was low (25.7 years); this finding is in agreement with the majority of previous reports on the association of C. trachomatis infection and younger age in women $^{26,28}$. Although most $C$. trachomatis cases are poorly symptomatic, a chronic and persistent infection may lead to 


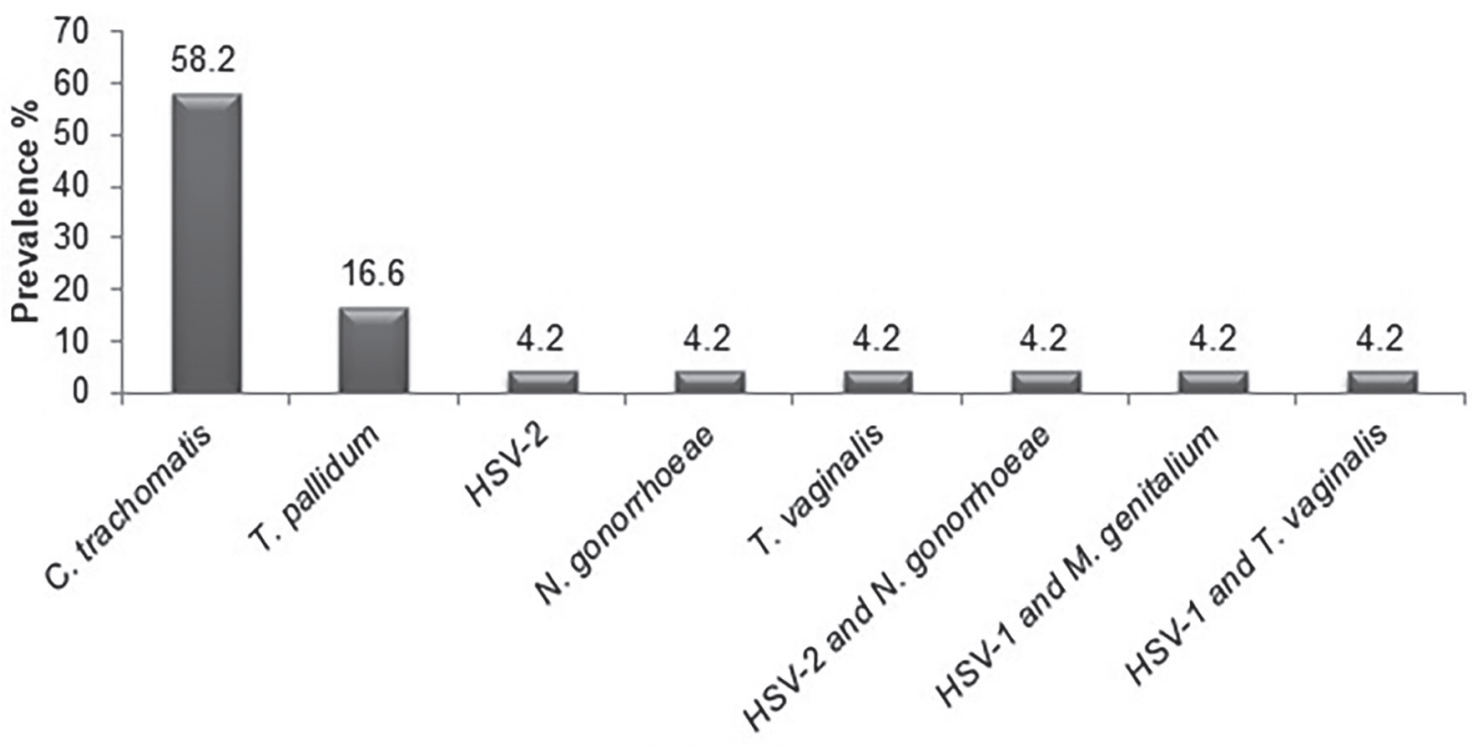

STI agents

Figure 1 - Prevalence of non-HPV STIs agents in STI-positive women $(n=24)$. Infections were assessed by multiplex-PCR.

Table 4 - Coinfection of different HPV genotypes with other STI agents

\begin{tabular}{lccc}
\hline STI agent & HR-HPV & $\begin{array}{c}\text { Probably } \\
\text { oncogenic }\end{array}$ & LR-HPV \\
\hline C. trachomatis & $16,18,45$, & 70 & 11,43 \\
N. gonorrhoeae & 59 & 68 & - \\
T. pallidum & 51 & 66 & - \\
T. vaginalis & 16 & - & - \\
HSV-1/M. genitalium & 16 & - & - \\
\hline
\end{tabular}

HSV-1/2 = Herpes simplex virus; HR-HPV = High-risk HPV; LR-HPV = Low-risk HPV

severe complications for women's health ${ }^{2,20}$. Therefore, it is extremely important to diagnose this infection in young asymptomatic women. In this sense, currently, there has been a great advance and improvement in $C$. trachomatis control, and prevention programs worldwide recommend that all sexually active females of 25 years of age or younger should undergo an annual screening 29,30 .

The number of $T$. pallidum infected individuals is increasing in many countries, emphasizing the need of early diagnoses $^{2}$. In the present study, the prevalence of syphilis was $1.9 \%$. Similar results were obtained by Abreu et al. ${ }^{31}$ (1.7\%) in Brazilian women using PCR-based methods. And other Brazilian studies obtained lower results in women tested by serological methods ${ }^{32,33}$.

$N$. gonorrhoeae, T. vaginalis, HSV1/2, and $M$. genitalium were also detected in the present study. They have been frequently investigated with different prevalence rates depending on the population characteristics and methodology $6,31,34,35$.

Several authors have found an association of host epidemiological characteristics such as multiple sexual partners, smoking habit, oral contraceptive use, and age of the first sexual intercourse ${ }^{6,36}$ with persistence of HPV. However, many studies have not replicated this association; therefore, there is no consensus regarding the cofactors leading to the persistence of HPV infection ${ }^{7,36}$. Our analysis showed an association with the presence of HPV for age groups younger than 25 years and those women who had more than one partner during their lives.

The vast majority $(90.5 \%)$ of women in this study did not present with cytological abnormalities and among them, 28.4\% were HPV-DNA-positive. Similar results regarding the lack of cytological changes have been shown by another study conducted among university students from Northern Brazil; the authors found no cytological abnormalities in $85.7 \%$ of women, and $23.4 \%$ of them were HPV-positive ${ }^{21}$. An investigation involving university women in Central Brazil observed high rates of HPV in participants with normal cytology 22 .

In a meta-analysis of worldwide data, Bruni et al. ${ }^{37}$ showed that only $11.7 \%$ of women with normal cytology had detectable DNA-HPV; however, in the current study the mean population age was different. Thus, it appears that in younger women, the rate of HPV associated with normal cytological findings is higher, so that the estimate of HPV infection in NILM can vary among populations depending on the geographical region and age $\mathrm{e}^{25,37}$. Furthermore, only about $10-30 \%$ of women with detectable HPV-DNA show 
Table 5 - Overall rates of HPV and other STI agents in the study population based on cytological findings.

\begin{tabular}{|c|c|c|c|c|c|}
\hline \multirow[t]{2}{*}{ Overall } & $\begin{array}{c}\text { Total } \\
(n=210)\end{array}$ & $\begin{array}{c}\text { NILM } \\
(n=190)\end{array}$ & $\begin{array}{c}\text { Abnormal } \\
(n=20)\end{array}$ & \multirow[t]{2}{*}{ OR $(95 \% \mathrm{Cl})$} & \multirow[t]{2}{*}{$P$} \\
\hline & \multicolumn{3}{|c|}{$\mathrm{n}(\%)$} & & \\
\hline HPV-DNA & $71(33.8)$ & $54(28.4)$ & $17(85.0)$ & $14.27(4.23-46.91)$ & $<0.0001$ \\
\hline LR-HPV & $17(24)$ & $14(7.4)$ & $3(15.0)$ & $1.12(0.49-2.42)$ & 0.83 \\
\hline Probably oncogenic & $12(16.9)$ & $10(5.3)$ & $2(10)$ & $2.00(0.41-8.51)$ & 0.31 \\
\hline HR-HPV & $42(59.1)$ & $30(15.8)$ & $12(60.0)$ & $8.00(3.02-21.25)$ & $<0.0001$ \\
\hline HPV 16 & $22(31.0)$ & $12(6.3)$ & $10(50.0)$ & $14.83(5.39-42,92)$ & $<0.0001$ \\
\hline HPV multiple infections & $30(42.2)$ & $23(12.1)$ & $7(35.0)$ & $3.91(1.49-10.83)$ & 0.001 \\
\hline HPV and STI & $10(4.8)$ & $7(3.7)$ & $3(15.0)$ & $4.61(1.19-19.60)$ & 0.056 \\
\hline Non-HPV STIs & $24(11.4)$ & $21(11.0)$ & $3(15.0)$ & $1.42(0.41-4.67)$ & 0.70 \\
\hline Chlamydia trachomatis & $14(58.3)$ & $12(6.3)$ & $2(10)$ & $1.64(0.34-6.58)$ & 0.62 \\
\hline HSV-2 & $1(4.2)$ & $1(0.5)$ & - & - & - \\
\hline Neisseria gonorrhoeae & $1(4.2)$ & $1(0.5)$ & - & - & - \\
\hline Treponema pallidum & $4(16.7)$ & $4(2.1)$ & - & - & - \\
\hline Trichomonas vaginalis & $1(4.2)$ & - & $1(5.0)$ & - & - \\
\hline HSV-1 and T. vaginalis & $1(4.2)$ & $1(0.5)$ & - & - & - \\
\hline HSV-1 and M. genitalium & $1(4.2)$ & $1(0.5)$ & - & - & - \\
\hline HSV-2 and N. gonorrhoeae & $1(4.2)$ & $1(0.5)$ & - & - & - \\
\hline
\end{tabular}

LR-HPV = Low-risk HPV; HR-HPV = High-risk HPV; HSV = 1/2-Herpes simplex virus

cytological abnormalities ${ }^{25}$, and our results corroborated these data.

In the present study, abnormal cytology was found in $9.5 \%$ of women, represented by $7.1 \%$ ASC-US and $2.4 \%$ LSIL. Vieira et al. ${ }^{21}$ have shown a low prevalence of abnormal cytology (2.3\% for HSIL, $0.4 \%$ for ASC-H, $6.4 \%$ for LSIL, and 5.3\% for ASC-US) among university students, in Brazil. Rabelo-Santos et al. ${ }^{22}$ detected cytological abnormalities in $8.7 \%$ of all suitable cervical university students' smears in a study conducted in Central Brazil, and HSIL was not present. In Canada, an investigation found a prevalence of $7.2 \%$ ASC-US, 3.4\% LSIL, and $0.8 \%$ HSIL in the same type of population ${ }^{24}$. Cervical abnormalities may develop decades after the HPV infection and are, therefore, less frequent in younger populations. Among abnormal cytological findings, the majority $(85.0 \%)$ were positive for HPV-DNA as expected ${ }^{38}$.

The statistical analysis showed that the detection of HPV, HR-HPV, HPV16 and multiple HPV infections were associated with the presence of cytological abnormalities. Our results are in accordance with several studies demonstrating this correlation ${ }^{10,12,39}$.

A marginal statistical significance between HPV associated with other STIs was observed according to the cytological findings. Several studies have reported that other STIs, especially C. trachomatis, increase the risk of acquiring an HPV infection and/ or are associated with the development of intraepithelial lesions ${ }^{40,41}$, but others did not find this association ${ }^{42}$.

\section{CONCLUSION}

The majority of HPV-positive patients did not return for follow-up so that it was not possible to verify data on the history of previous HPV infections from these women, which limits our interpretations on the persistence of HPV and its influence on the genesis of cytological abnormalities. In addition, the frequency of coinfections between HPV and other STI agents was low to enable a suitable evaluation on the influence of this association in abnormal cytology findings. In conclusion, the present study has shown a high prevalence of HPV and C. trachomatis as important STI agents, in younger asymptomatic university women accompanied by low rates of cytological abnormalities. Multiple HPV infections were also frequent, and the most prevalent genotype was HPV16. These results highlight the need to adopt public policies for the prevention and early diagnosis of STIs in young and asymptomatic women and to prevent future consequences, including the development of cervical lesions and cancer. 


\section{ACKNOWLEDGMENTS}

This work was supported by Conselho Nacional de Desenvolvimento Cientifico e Tecnologico (CNPq), grant No 484994/2013-1.

\section{AUTHORS' CONTRIBUTIONS}

MEL and VRSS conceived and designed the work, analysed and interpreted the data; CGB participated in the design of work and in the analysis and interpretation of data; TTS, FG and RPS performed the experimental procedures, acquisition and analysis of data; SKIT and RCCC assisted the patients and collected samples. MMTI performed the Pap test evaluation; TTS, MEL and VRSS wrote and revised the article. The authors approve the final version of the manuscript and are responsible for all its aspects.

\section{CONFLICT OF INTERESTS}

The authors declare no conflict of interests.

\section{REFERENCES}

1. World Health Organization. Report on global sexually transmitted infection surveillance, 2018. Geneva: WHO; 2018. [cited 2020 Dec 4]. Available from: https://apps.who.int/iris/bitstream/ha ndle/10665/277258/9789241565691-eng.pdf?ua=1

2. Centers for Disease Control and Prevention. Sexually transmitted disease surveillance 2017. Atlanta: CDC; 2018. [cited 2020 Dec 4] Available from: https://www.cdc.gov/std/stats17/2017STD-Surveillance-Report_CDC-clearance-9.10.18.pdf

3. Masha SC, Cools P, Sanders EJ, Vaneechoutee M, Crucitti T. Trichomonas vaginalis and HIV infection acquisition a systematic review and meta-analysis. Sex Trans Infect. 2019;95:36-42.

4. Newman L, Rowley J, Vander Hoorn S, Wijesooriya NS, Unemo M, Low N, et al. Global estimates of the prevalence and incidence of four curable sexually transmitted infections in 2012 based on systematic review and global reporting. PLoS One. 2015;10:e0143304.

5. Ferlay J, Colombet M, Soerjomataram I, Mathers C, Parkin DM, Piñeros M, et al. Estimating the global cancer incidence and mortality in 2018: GLOBOCAN sources and methods. Int J Cancer. 2019;44:1941-53.

6. Verteramo R, Pierangeli A, Mancini E, Calzolari E, Bucci M, Osborn

$\mathrm{J}$, et al. Human Papillomaviruses and genital co-infections in gynaecological outpatients. BMC Infect Dis. 2009;9:16.

7. Ribeiro AA, Costa MC, Alves RR, Villa LL, Saddi VA, Carneiro MA, et al. HPV infection and cervical neoplasia: associated risk factors. Infect Agent Cancer. 2015;10:16.
8. International Collaboration of Epidemiological Studies of Cervical Cancer. Carcinoma of the cervix and tobacco smoking: collaborative reanalysis of individual data on 13,541 women with carcinoma of the cervix and 23,017 women without carcinoma of the cervix from 23 epidemiological studies. Int J Cancer. 2006;118:1481-95.

9. Moreno V, Bosch FX, Muñoz N, Meijer CJ, Shah KV, Walboomers $\mathrm{JM}$, et al. Effect of oral contraceptives on risk of cervical cancer in women with human papillomavirus infection: the IARC multicentre case-control study. Lancet. 2002;359:1085-92.

10. Suehiro TT, Malaguti N, Damke E, Uchimura NS, Gimenes F, Souza RP, et al. Association of human papillomavirus and bacterial vaginosis with increased risk of high-grade squamous intraepithelial cervical lesions. Int J Gynecol Cancer. 2019;29:242-9.

11. Zereu M, Zettler CG, Cambruzzi E, Zelmanowicz A. Herpes simplex virus type 2 and Chlamydia trachomatis in adenocarcinoma of the uterine cervix. Gynecol Oncol. 2007;105:172-5.

12. Abreu AL, Malaguti N, Souza RP, Uchimura NS, Ferreira EC, Pereira MW, et al. Association of human papillomavirus, Neisseria gonorrhoeae and Chlamydia trachomatis coinfections on the risk of high-grade squamous intraepithelial cervical lesion. Am J Cancer Res. 2016;6:1371-83.

13. Souza RP, Abreu AL, Ferreira EC, Rocha-Brischiliari SC, Carvalho MD, Pelloso SM, et al. Simultaneous detection of seven sexually transmitted agents in human immunodeficiency virus-infected Brazilian women by multiplex polymerase chain reaction. Am J Trop Med Hyg. 2013;89:1199-202.

14. Solomon D, Nayar R. Sistema Bethesda para citopatologia cervicovaginal: definições, critérios e notas explicativas. $2^{\mathrm{a}}$ ed. Rio de Janeiro: Revinter; 2005.

15. Brasil. Ministério da Saúde. Instituto Nacional de Câncer José Alencar Gomes da Silva. Coordenação de Prevenção e Vigilância. Divisão de Detecção Precoce e Apoio à Organização de Rede. Diretrizes brasileiras para o rastreamento do câncer do colo do útero. $2^{\mathrm{a}}$ ed. Rio de Janeiro: INCA; 2016. [cited 2020 Dec 4] Available from: https://www. inca.gov.br/sites/ufu.sti.inca.local/files//media/document// diretrizesparaorastreamentodocancerdocolodoutero_2016_ corrigido.pdf

16. Manos MM, Waldman J, Zhang TY, Greer CE, Eichinger G, Schiffman $\mathrm{MH}$, et al. Epidemiology and partial nucleotide sequence of four novel genital human papillomaviruses. Infect Dis. 1994;170:1096-9.

17. Santiago E, Camacho L, Junquera ML, Vázques F. Full HPV typing by a single restriction enzyme. J ClinVirol. 2006;37:38-46.

18. Chen L, Watanabe K, Haruyama T, Kobayashi N. Simple and rapid human papillomavirus typing method by restriction fragment length polymorphism analysis with two restriction enzymes. J Med Virol. 2013;85:1229-34. 
19. HPV Information Centre. [cited 2020 Dec 4]. Available from https://hpvcentre.net/

20. Brasil. Ministério da Saúde. Secretaria de Vigilância em Saúde. Departamento de DST, Aids e Hepatites Virais. Protocolo clínico e diretrizes terapêuticas para atenção integral às pessoas com infecções sexualmente transmissíveis. Brasília: Ministério da Saúde; 2015. [cited 2020 Dec 4] Available from: https:// bvsms.saude.gov.br/bvs/publicacoes/protocolo_clinico_ diretrizes_terapeutica_atencao_integral_pessoas_infeccoes_ sexualmente_transmissiveis.pdf

21. Vieira RC, Monteiro JS, Manso EP, Santos MR, Tsutsumi MY, Ishikawa EA, et al. Prevalence of type-specific HPV among female university students from northern Brazil. Infect Agent Cancer. 2015;10:21.

22. Oliveira DF, Pereira RN, Alves RR, Saddi VA, Sousa NA, Ribeiro AA, et al. Association between human papillomavirus infection and cytological abnormalities in young female university students in Central Brazil. Cytol Histol Int J. 2017;1:000101.

23. Auvinen E, Niemi M, Malm C, Zilliacus R, Trontti A, Fingerroos $\mathrm{R}$, et al. High prevalence of HPV among female students in Finland. Scand J Infect Dis. 2005;37:873-6.

24. Richardson H, Franco E, Pintos J, Bergeron J, Arella M, Tellier P. Determinants of low-risk and high-risk cervical human papillomavirus infections in Montreal university students. Sex Transm Dis. 2000;27:79-86.

25. IARC Working Group on the Evaluation of Carcinogenic Risks to Humans. Biological agents: volume $100 \mathrm{~B}$ : a review of human carcinogens. IARC Monogr Eval Carcinog Risks Hum. 2012;100:1-441.

26. Santos C, Teixeira F, Vicente A, Astolfi-Filho S. Detection of Chlamydia trachomatis in endocervical smears of sexually active women in Manaus-AM, Brazil, by PCR. Braz J Infect Dis. 2003;7:91-5

27. Tavares MC, Macêdo JL, de Lima Junior SF, Heráclio SA, Amorim MM, Maia MM, et al. Chlamydia trachomatis infection and human papillomavirus in women with cervical neoplasia in Pernambuco-Brazil. Mol Biol Rep. 2014;41:865-74.

28. Santos LM, Vieira MR, Oliveira JF, Trindade JQ, Brasiliense DM, Ferrari SF, et al. High prevalence of sexual Chlamydia trachomatis infection in young women from Marajó Island, in the Brazilian Amazon. PLoS One. 2018;13:e0207853.

29. Public Health England. National chlamydia screening programme standards. $7^{\text {th }}$ ed. London: Public Health England; 2018. [cited 2020 Dec 4] Available from: https://assets.publishing.service. gov.uk/government/uploads/system/uploads/attachment_ data/file/759846/NCSP_Standards_7th_edition_update_ November_2018.pdf

30. Keegan MB, Diedrich JT, Peipert JF. Chlamydia trachomatis infection: screening and management. J Clin Outcomes Manag. 2014;21:30-8.
31. Abreu A, Souza R, Bonini M, Gimenes F, Consolaro ME. Human Papillomavirus and sexually transmitted infections in women with and without abnormalities in cervical cytology. Biochem Mol Biol J. 2015;29:LB126.

32. Lima YA, Turchi MD, Fonseca ZC, Garcia FL, Cardoso FA, Reis MN, et al. Sexually transmitted bacterial infections among young women in Central Western Brazil. J Infect Dis. 2014;25:16-21.

33. Oliveira FA, Pfleger V, Lang K, Heukelbach J, Miralles I, Fraga F. et al. Sexually transmitted infections, bacterial vaginosis, and candidiasis in women of reproductive age in rural Northeast Brazil: a population-based study. Mem Inst Oswaldo Cruz. 2007;102:751-6.

34. Seña AC, Lee JY, Schwebke J, Philip SS, Wiesenfeld HC, Rampalo $\mathrm{AM}$, et al. A silent epidemic: the prevalence, incidence and persistence of Mycoplasma genitalium among young, asymptomatic high-risk women in the United States. Clin Infect Dis. 2018;67:73-9.

35. Francis SC, Mthiyane TN, Baisley K, Mchunu SL, Ferguson JB, Smit T, et al. Prevalence of sexually transmitted infections among young people in South Africa: a nested survey in a health and demographic surveillance site. PLoS Med. 2018; $15:$ : 1002512.

36. Fedrizzi EN, Schlup CG, Menezes ME, Campos M. Infecção pelo papilomavírus humano (HPV) em mulheres de Florianópolis, Santa Catarina. DST J Bras Doenças Sex Transm. 2008;20:739.

37. Bruni L, Diaz M, Castellsagué M, Ferrer E, Bosch FX, Sanjosé S. Cervical human papillomavirus prevalence in 5 continents: meta-analysis of 1 million women with normal cytological findings. J Infect Dis. 2010;202:1789-99.

38. Consolaro ME, Maria-Engler SS, organizadoras. Citologia clínica cérvico-vaginal: texto e atlas. São Paulo: Roca; 2012.

39. Parthenis C, Panagopoulos P, Margari N,Kottaridi C, Spathis A, Pouliakis A, et al. The association between sexually transmitted infections, human papillomavirus, and cervical cytology abnormalities among women in Greece. Int J Infect Dis. 2018;73:72-7.

40. Liu J, Liu W, Liu Y, Zhou X, Zhang Z, Sun Z. Prevalence of microorganisms co-infections in human papillomavirus infected women in Nothern China. Arch Gynecol Obstet. 2016;293:595-602.

41. Karim S, Souho T, Benlemlih M, Bennani B. Cervical cancer induction enhancement potential of Chlamydia trachomatis: a systematic review. Curr Microbiol. 2018;75:1667-74.

42. Magalhaes PA, Miranda CA, Lima EG, Moizéis RN, Lima DB, Cobucci RN, et al. Genital tract infection with Chlamydia trachomatis in women attended at a cervical cancer screening program in Northeastern from Brazil. Arch Gynecol Obst. 2015;291:1095-102. 